\title{
Digital Platform Business Systems Reshaping the Business World
}

\author{
Anna Cui ${ }^{1 *}$ \\ ${ }^{1}$ Tsinghua International School, Beijing 100084, China \\ *anna_cui22@this.edu.cn
}

\begin{abstract}
In a traditional market, having multiple prices on the same good or service is common because of geographical barriers, information asymmetry, transportation costs, and other limitations. However, platform-type companies have the potential to break these barriers by connecting numerous consumers and producers, stabilizing the market price at equilibrium, and challenging the traditional economic theories. This type of business model gained popularity quickly in the recent decades and grew at a conspicuous speed due to new technologies and innovations. In this paper, empirical analysis on the platform system's fundamental components, efforts to maintain balance, and stages of growth are presented along with relevant case studies.
\end{abstract}

Keywords: digital platform, business model, critical mass, indirect network effect, scale economy

\section{INTRODUCTION}

In recent decades, digital and mobile technologies grew and spread at a remarkable speed. Innovations such as cognitive computing and digital reality are reshaping the business world, significantly impacting and encouraging market changes [1]. They have the incredible power to rewrite the rules of business and innovation [2]. Along with the emergence of new information and communication technologies (ICT), a conspicuous growth of digital-enabled platform business models becomes one of the most compelling transformations been at a global level [3][4].

Platform-type companies act as intermediates, developing and managing an aggregated goods and services of the same kind [5]. Although platforms are common in the long history, the use of collaborative operations and network systems revolutionized the model. Just as some other scholars predicted, it has the potential to become the core organizing principle of the new economy [6][7]. The internet, social network, and big data catalyzed the advent of platform-type companies which connects multiple separate retailers. Digitalenabled platform systems are initially observed in the $90 \mathrm{~s}$, which then grew rapidly after 2000. Especially under the Covid-19 pandemic in 2020, platform business models gained popularity in an unprecedented way, increasing shares in the real economy and stock market. This restructuring of the market needs new economic principles to explain its deviation from conventional theories. This paper investigates characteristics of a platform system to help analyze its business model, which could potentially assist further research into the new structure of the economy.

\section{EMPIRICAL ANALYSIS OF THE PLATFORM SYSTEM}

\subsection{Fundamental Components}

\subsubsection{Overview}

A platform business model consists of three integral parts: a platform-type company and at least two groups of customers. For demonstration purposes, we assume the platform has two groups of customers.

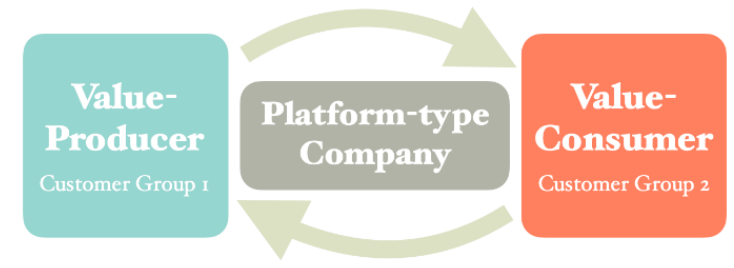

Figure 1 Platform Business Model Overview (Source: author's elaboration) 


\subsubsection{Customer Groups}

The two groups of customers are the participants in the system, often having different roles of producers who create value and consumers who consume value [5]. The seemingly distinct customer groups are connected through interdependent demands and in the meantime, the platform-type company acts as an intermediary that internalizes the resulting indirect network externalities [8]. As shown in Table 1, the customer groups can vary dramatically from industry to industry. Sometimes customer groups play considerably different roles such as developers and end-users in a software platform, other times like in a payment system, however, customers can switch from being a payer or a receiver easily depending on the transaction.

\begin{tabular}{|l|l|l|}
\hline Examples of System & Customer Group I & Customer Group 2 \\
\hline Exchange platform & Buyer & Seller \\
\hline Advertising-supported media & Advertiser & Public audience \\
\hline Payment system & Payer & Receivers \\
\hline Software platform & Program developer & End-user \\
\hline
\end{tabular}

Table 1 Customer Groups of Different Platforms (Source: author's elaboration)

Platform business model is frequently introduced as an innovation that provides users or business participants the possibility of immediate communication [9]. This inevitably influences the market:

On a larger scope, platform-type companies have the potential to establish monopolies and control the overall market behavior. These companies connect the individual value-producers together and present them to aggregated value-consumers altogether.

On a smaller scope within the platform, competition among value-producers increases significantly. With clear choices shown explicitly and being compared in front of the value-consumers, prices are forced to become lower in order for the product to have a stand in the competitive market. This stabilizes price at a relatively low level, flattening the supply curve and shifting the demand curve to the right, as shown in Figure 2.
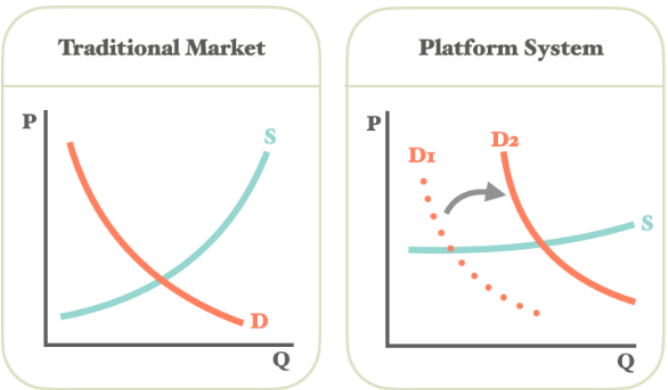

Figure 2 Platform System's Deviation on Supply and Demand Curve (Source: author's elaboration)

\subsubsection{Platform-type Company}

Platform-type companies serve as intermediates that make the interaction between pairs of customers easier. In addition to providing opportunities for the two groups to meet each other, they also create standards, protocols, and policies to build an ideal business eco-system [10]. In other researches, various names have been given to the same model, which includes: digital platforms [5], platfirms [11], vertical search engines [12], multi-sided platforms [13], and two-sided markets [14].

In conventional economics, supply and demand curves are created by numerous points, modeling the price determination in a market. Because of limitations like geographical barriers, transportation costs, information asymmetry, multiple prices of identical goods and services become common. Therefore, each point on the supply curve could be seen as a retailer like a supermarket, a store, or a mall with different pricing. platform-type companies have the potential to connect multiple separate retailers into a super-dot, challenging the traditional economic theories. In this scenario, the company that owns the super-dot has the great potential to monopolize the market and increase its scale continuously.

Although a platform monopoly has the power to manipulate the overall market, its ultimate goal is to profit for the company itself. More specifically, there are multiple revenue streams from which a platform-type company gains profit, and as shown in Figure 3, marginal revenue and secondary demands are the key revenue streams of platform-type companies.

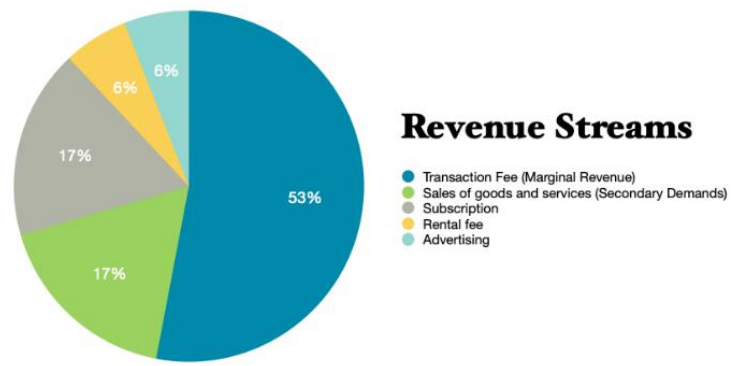

Figure 3 Differences in Revenue Streams (Source: Ruggieri et al.)

Platform-type companies charge a small fee for every successful transaction made between the two customer groups they are serving to create marginal revenue. The fee needs to be low enough to not interrupt and affect the decision of transactions. The most typical form of marginal revenue that people often notice, for example, is the small transaction fee that banking systems charge.

As stated previously, the two customer groups meet each other's primary needs interdependently. Meanwhile, platform-type companies could profit by meeting the secondary demands through providing alternative forms, such as direct sales of goods and services to the customer 
groups. However, secondary demand should not be considered as a stable revenue stream for the platformtype company.

\subsection{Attaining Balance of the System}

\subsubsection{The Critical Mass}

A platform provider needs to achieve a critical user base to function organically, and the point of critical mass describes the scale of populations of customer groups required for it to grow self-sustainably. As shown in Figure 4, the populations of both customer groups are independent values that stretch a "net" to reach the virtual point. When reached, the platform-type companies could lower the marginal cost of acquiring new customers as influencers and connectors impact the system dramatically. This is essential since businesses are increasingly aware of the cost-benefit from platform business such as cloud-based services [15].

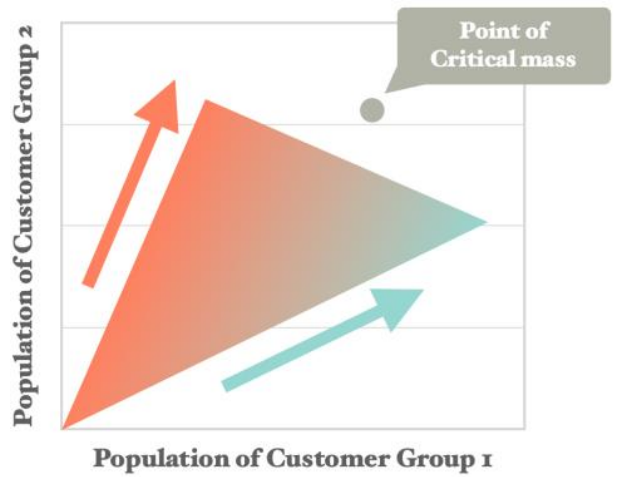

Figure 4 Virtual Graph Demonstration of the Critical Mass Theory. (Source: author's elaboration)

If the demand from one side diminishes, the demand from the other side vanishes along despite the change in price. Therefore, to balance the size of the two customer groups, platform-type companies could even apply an approach that is essentially harmful to one group. Price discrimination is one of the most common ways to acquire balance in the number of customers, and even if over-discounting created a loss to the platform provider, the profit generated from the other group of customers has the potential to compensate for it.

\subsubsection{Externality \& Indirect Network Effect}

As an intermediary, platform-type companies profit by internalizing externalities created by one group for another. However, customer groups can enter a bilateral transaction and internalize the indirect externalities themselves without a bridging unit [13]. For example, one can pay cash directly instead of going through a third party like a bank to avoid paying the transaction fee. Therefore, platform providers naturally have strong incentives to discourage customer groups to figure out the externality themselves. That is, platform-type companies need to increase their customers' reliance.

A strategic way to increase bargaining power from customers is by using the indirect network effect. In an effort to better serve their customers, social media platforms and other virtual content platforms influence adapting changes from conventional consumer behaviors and retailing services [16]. The great convenience resolves a great pain point of the customers, thus raising the platform's value proposition. In fact, customers are also actively engaging in the value creation process through user-added values, include but are not limited to providing user-generated content and user-generated creativity [17]. This is one of the main reasons why platform-type companies become more commonly seen in everyday life, and this cycle of indirect network effect has the great potential to lead to a monopoly situation, as seen in multiple social media platforms.

\subsubsection{Scale Economy}

Scale economy is expected, sometimes required, for a successful platform because when excessive choices are offered, congestion occurs. Platform-type companies could be impacted negatively because including irrelevant information could higher search costs to manage the data. On the customer side, value-consumers could be distracted with an exceeding amount of information while value-producers would compete more intensely with additional pressure. As a result, finding the right scale and balance is crucial.

However, it is also conceivable that the marginal cost for platform-type companies to decrease continuously and even approaching zero due to the increasing development and innovation. Then, a few monopolistic companies might gain authority over the entire market, having the potential to establish immense capital and resources.

\subsection{Stages of Successful Growth}

\subsubsection{Stage 1: Establishing Monopoly}

For a platform-type company, the first stage towards success is to establish a monopoly in a single market. That is, to have dominating power over one specific good or service. The key purpose of this initial step is to formulate loyalty on the mass value-consumer side.

Platform-type companies first institute presence in small markets, and later uses rial and error to identify the suitable operations to invest in [13]. Originally, customers are mainly adopters of the new product due to external influences, which requires an enormous amount of investing. Some platforms choose to attract customers through free or even deficit service with the cost being called the customer acquisition cost (CAC), others 
choose to lower entry cost by heavily investing in one side of the market.

Adopters due to internal influence expand rapidly afterward, being a key measure to a growth performance of the platform. The influencers and the connectors play significant roles in enlarging the platform after the critical mass is reached. Influencers are people who have disproportionate communication power; connectors are people who have connections to many isolated customers. However, the platform-type company is still likely to be in overall deficit throughout the entire stage.

\subsubsection{Stage 2: Expanding Scale}

The second stage is to extend the scale of the platform by increasing the number of goods and services. Since all the value-consumers are already part of the platform system at the first stage, this step's foremost goal is to attract as many value-producers across different industries as possible. If successful, the supply side would spread swiftly. This stage often creates little or no profit.

\subsubsection{Stage 3: Adding Value Proposition}

By this stage, all the potential customers are attracted and included in the platform system, reaching saturation. The platform-type system then continuously provides value-adding services to existing customers which could affect the overall system to be more convenient, attractive, and reliable. This includes opportunity or usage of advertisements, data server, delivery network, entertainment, etc.

After all, a platform-type company is an IT and network-oriented company. This requires them to invest heavily in research and development at the previous stages, so this last stage of adding value is the crucial period of increasing profit.

\section{CASE STUDY}

\subsection{Methodology}

Platform business model is a core concept, or a theory, which can develop into various forms due to the complexness of practical needs in society. In this scenario, case studies of empirical evidence could play a pivotal role in an effective analysis, which is a preferred method when studying platform businesses as it takes the network of participants in shared innovation strategies into consideration [15]. Business case studies present rich descriptions of particular stances of a phenomenon that are typically based on a variety of data sources [18].

While there are numerous unique characteristics of the platform business model, this case study section mainly discusses the stages of growth for a successful platform-type company. Meituan and Amazon are chosen to contrast platforms that started with service and good, respectively.

\subsection{Meituan}

Meituan is the world's largest on-demand food delivery service provider. In another word, it successfully finished the first stage of establishing a monopoly by providing a service. By 2020 , Meituan has 510.6 million transacting users, 6.8 million active merchants, and 488,851.2 million gross transaction volume of food delivery. A strong consumer base, merchant base, and delivery network generates a powerful network effect and enables solid growth [19]. By connecting separate sellers and consumers in the food industry across entire China, Meituan gained an absolute advantage over the service in terms of scale and consumer loyalty. To achieve utility maximization, the company chose to sacrifice the value-producers side as the merchants have strong reliability on the platform due to the benefits of growing beyond physical boundaries and the increasing competitiveness in the market. As a result, $88.48 \%$ of Meituan's revenue from food delivery services is from commissions, a fee that is charged to merchants [19].

Meituan is currently at the beginning of the second stage, expanding the services it provides. This includes hotel booking, bike-sharing, car-hailing, movie ticket ordering, and other dozens of services, as shown in Figure 4. This indicated that Meituan emphasizes absolute advantage in services in the status quo. While food delivery is still its main source of revenue, services relating to traveling also increasingly create value.

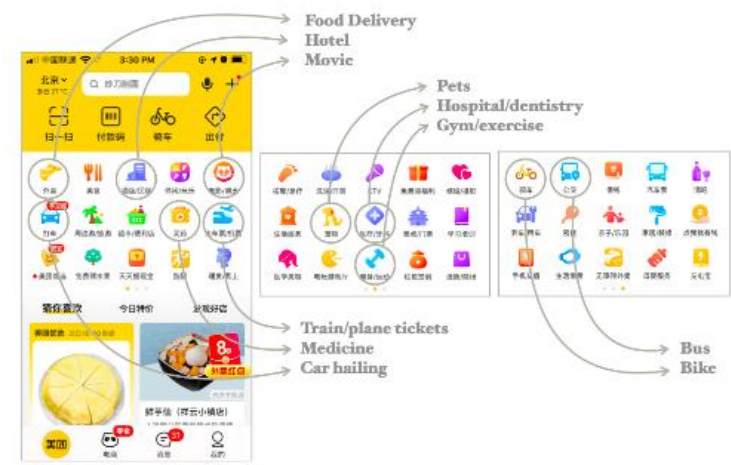

Figure 4 Meituan Expanding Services. (Source: author's elaboration)

\subsection{Amazon}

Initially, Amazon created a platform using a single type of good, which is books. Throughout the formation of the system, Amazon brought all the suppliers and consumers together and created an absolute advantage on price to reach a monopoly. This process takes a long period as it requires the population of value-consumers to reach a high standard in order to move on to the second 
step. The fundamental characteristic of completing the first stage is the consumer side's absolute loyalty to this particular platform by solving barriers from the traditional economic system.

In the second stage of expanding the scale, Amazon continuously expands the number of goods on the platform. Since the value-consumer side is basically saturated, this stage is enlarging the value-producer side. Eventually, Amazon became the so-called "Everything Store".

Amazon is one of the most successful platform-type companies, and it entered the third stage. While the two customer groups are stable in general, the population involved in this platform system no longer presents obvious growth. But through this platform system, Amazon brings value-adding services such as advertising and entertainment to achieve profitability. Amazon has excellent customer service and ensured customer satisfaction as it built a peer review system, easy checkouts, user-tailored suggested products [20].

\section{CONCLUSION}

The platform system is a new type of business model enabled by the advancement of digital technologies. Unlike traditional transaction processes, platform-type companies serve as intermediates that connect aggregated crowds of customers then profits from between via revenue streams like marginal revenue and secondary demand. By maintaining the balance of population ratio, scale, and others, a successful platformtype company has the strong potential to establish a monopoly across multiple industries.

The unique way platform system functions are restructuring the business world. As they deviate from traditional economic theories such as supply and demand, new principles are currently needed to fully explain and analyzed the phenomenon. From conventional standpoints from the last few centuries, production is determined by labor, capital, and technology. But in the new digital-enabled platform business model, factors that influence a company's production would change. The limitation of this paper is that it merely analysed the characteristics and observed the changes in the current economy, further studies and researches on the digital network are needed to build new economic theories.

\section{REFERENCES}

[1] DXC. Technology. (2021) Technology: Industry Overview.

https://www.dxc.technology/technology/insights/1 45881-technology_industry_overview.

[2] Stoian, C. A., Tohanean, D. (2021) Platform Business Models - A Case Study of the Technology Industry. Journal of Economics and Management.
[3] Breidbach, C. F., and Maglio, P. P. (2016) Technology-enabled value co-creation: An empirical analysis of actors, resources, and practices. Industrial Marketing Management, 56, pp. 73-85.

[4] West, S., Gaiardelli, P., and Rapaccini, M. (2018) Exploring technology-driven service innovation in manufacturing firms through the lens of Service Dominant logic. IFAC-PapersOnLine, Vol. 51, No. 11, pp. 1317-1322. Complexity, ISSN 2199-8531, Springer, Heidelberg, Vol. 1, Iss. 6, pp. 1-14, http://dx.doi.org/10.1186/s40852-015-0006-8.

[5] Ruggieri, R., Savastano, M., Scalingi, A., Bala, D., and D'Ascenzo, F. (2018) The Impact of Digital Platforms on Business Models: an empirical investigation on innovative start-ups. Management \& Marketing, Challenges for the Knowledge Society, Vol., 13, No 4, pp. 1210-1225. DOI: 10.2478/mmcks-2018-0032.

[6] Kenney, M., \& Zysman, J. (2016) The Rise of the Platform Economy. Issues in Science and Technology, 32, 61-69.

[7] Parker, G. G., van Alstyne, M., \& Choudary, S. P. (2016) Platform revolution: How networked markets are transforming the economy - and how to make them work for you. (First edition).

[8] Rochet, J. C., Jean T. (2003) Platform Competition in Two-Sided Markets. Journal of the European Economics Association (forthcoming).

[9] Gawer, A., \& Cusumano, M. A. (2014) Industry Platforms and Ecosystem Innovation. Journal of Product Innovation Management, 31(3), 417-433. https://doi.org/10.1111/jpim.12105.

[10] Kim, J. (2016) The platform business model and strategy: a dynamic analysis of the value chain and platform business. Manchester.

[11] Harvard Business Review. (2016) The Platfirm Age.

[12] Chau, M., and Chen, H. (2003) Comparison of three vertical search spiders. Computer, Vol. 36, No. 55, pp. 56-62.

[13] Evans, D. S. (2003) Some empirical aspects of multi-sided platform industries. Review of Network Economics, Vol. 2, No. 33, pp. 191-209.

[14] Evans, D. S. (2002) The antitrust economics of twosided markets. AEI-Brookings Joint Center of Regulatories Studies, Related Publication 02-13, September 2002.

[15] Deloitte. (2021) 2021 Outlook for the US Technology Industry. Deloitte Development LLC. https://www2.deloitte.com/content/dam/Deloitte/us 
/Documents/technology-media-

telecommunications/us-tmt-2021-outlook-for-theus-technology-industry.pdf.

[16] Grewal, D., Hulland, J., \& Kopalle, P. K. (2020) The future of technology and marketing: a multidisciplinary perspective. Journal of the Academy of Marketing Science, 48, 1-8. https://doi.org/10.1007/s11747-019-00711-4.

[17] Wirtz, B. W., Schilke, O., \& Ullrich, S. (2010) Strategic Development of Business Models. Long Range Planning, 43(2-3), 272-290. https://doi.org/10.1016/j.lrp.2010.01.005.

[18] Taeuscher, K., \& Laudien, M. (2018) Understanding platform business models: A mixed methods study of marketplaces. European Management Journal, 36(3), 319-329. https://doi.org/10.1016/j.emj.2017.06.005.

[19] Meituan. (2020) Meituan Annual Report 2020.

[20] University of Toronto. (2013) Amazon Business Model Case Study. Faculty of Applied Science and Engineering, Meng ELITE Program. 